\title{
Optimization of cholesterol oxidase production and 16S rRNA partial sequence of Bacillus cereus strain KAVK4 isolated from butter
}

\author{
Amutha Kuppusamy*, Kokila Vasantha Kumar \\ Department of Biotechnology, Vels University, Chennai, Tamil Nadu, India.
}

\section{ARTICLE INFO \\ Article history: \\ Received on: 15/03/2016 \\ Revised on: 20/04/2016 \\ Accepted on: 30/05/2016 \\ Available online: 28/07/2016}

Key words:

Bacillus cereus strain

KAVK4, Sequencing, 16S

rRNA gene, Cholesterol

oxidase, Optimization.

\begin{abstract}
The aim of the present research work was to optimize cholesterol oxidase production and partial sequencing of 16S rRNA gene region of Bacillus cereus strain KAVK4 by PCR. Bacillus cereus is a gram positive bacterium isolated from butter, Tamil Nadu, India and was cultured in a nutrient medium containing cholesterol at $37^{\circ} \mathrm{C}$ for 24 hours. Partial sequence of 16S rRNA gene was amplified by PCR and sequenced, the sequence data was submitted to NCBI. The production of cholesterol oxidase of Bacillus cereus strain KAVK4 was analyzed by qualitative methods such as Colony staining method \& Cholesterol Oxidase indicator plate method and quantitative method. The maximum production of cholesterol oxidase was checked in media with different carbon source, nitrogen source, and metal ions source. The different physical parameters like $\mathrm{pH}$, temperature and time were checked. Bacillus cereus strain KAVK4 partial sequence of 16S rRNA gene region resulted 1366bp. The sequence data was submitted to NCBI and the accession number is KP792775. Bacillus cereus strain KAVK4 was optimized at media containing Fructose, Beef Extract, Ammonium Nitrate and Magnesium sulphate at pH 7.5 at Room temperature and incubation period was about 32 hrs. Bacillus cereus strain KAVK4 was found to produce maximum level of cholesterol oxidase $(1.67 \mathrm{U} / \mathrm{ml})$. The result obtained in this work was clearly indicated that Bacillus cereus strain KAVK4 was capable of producing maximum level of cholesterol oxidase at $\mathrm{pH} 7.5$ and incubation was $32 \mathrm{hrs}$.
\end{abstract}

\section{INTRODUCTION}

The microbial degradation of cholesterol into 4cholesten-3-one by the cholesterol oxidase. The oxidation of cholesterol to 4-cholesten-3-one and the reduction of oxygen to hydrogen peroxide which catalyzes by the cholesterol oxidase (Smith and Brooks, 1976 and Sakodinskaya, 2000). It has been widely applied in medical field for the determination of cholesterol in blood serum and food. It acts as a starting material for the chemical synthesis of pharmaceutical steroid (Watanabe et al., 1986). It can also be employed for degrading dietary cholesterol to improve human health associated with cardiovascular disease (Kaunitz et al., 1978). Many microorganisms have an ability to decompose cholesterol that

\footnotetext{
* Corresponding Author

Dr. K. Amutha, Associate Professor Department of Biotechnology, Vels University, Pallavaram, Chennai Tamil Nadu, India

E Mail: amutharavi40@gmail.com
}

has been due to the enzyme source in steroid biotransformations, this was achieved by cholesterol oxidase (Constantinides, 1980). Cholesterol oxidase can be produced by bacteria of the genera Arthrobacter, Brevibacterium, Pseudomonas, Nocardia, Rhodococcus, Streptomyces, Corynebacterium and Shizophyllum (Yazdi et al., 2008). This can be produced in three forms such as intracellular, extracellular and membrane bounded. Cholesterol oxidase are widely applied in various fields, hence screening and isolate of cholesterol oxidase producing bacterial strains are of great interest (Yazdi et al., 2001a). Due to low production of Cholesterol oxidase many researchers may attempt to improve its yield by the modification of the growth medium (Lata Kumari et al., 2012). In the present study, Bacillus cereus strain KAVK4 was isolated from Butter and identified at molecular level by sequencing $16 \mathrm{~S}$ rRNA gene region. Then, the optimization of cholesterol oxidase production by Bacillus cereus strain KAVK4 using different media, carbon source, nitrogen source, metal ion source, $\mathrm{pH}$, Temperature and Time were performed in order to increase the cholesterol oxidase production. 


\section{MATERIALS AND METHODS}

\section{Isolation and identification of Bacillus cereus strain KAVK4}

The Butter sample was collected from Chennai, Tamil Nadu, India. The sample was serially diluted using $9 \mathrm{ml}$ sterile distilled water. The bacterial species was cultured by cholesterol containing nutrient medium at $37^{\circ} \mathrm{C}$ for 24 hours. Bacillus cereus was identified based on physical, morphological and biochemical characterization (Bergey's Manual of determinative bacteriology, Williams and Wilkins 1994).

\section{Molecular identification of Bacillus cereus}

DNA was extracted from Bacillus cereus based on the method described by Pitcher et al. (2008). After extraction the DNA sample was run on $1 \%$ agarose gel at a constant voltage of $100 \mathrm{~V}$. The gel was examined on UV transilluminator.

\section{PCR amplification and sequencing of $16 \mathrm{~S}$ rRNA}

$16 \mathrm{~S}$ rRNA gene region of Bacillus cereus was amplified.

For setting up PCR, the following reaction mixtures were added into the PCR tube (Applied Biosystems, Acme Progen Biotech (India) Pvt.Ltd, Salem, Tamilnadu, India).

Template- $5 \mu 1$

518Forward primer- $1 \mu \mathrm{l}$

800Reverse primer-1 $\mu \mathrm{l}$

Assay buffer- $6 \mu \mathrm{l}$

Taq DNA polymerase- $2 \mu \mathrm{l}$

dNTP mix- $5 \mu \mathrm{l}$

Using the following reaction conditions, the amplification was carried out in a thermal cycler for 40 cycles. Denaturation of DNA at $94^{\circ} \mathrm{C}$ for 1 minute, primer annealing at 56 ${ }^{\circ} \mathrm{C}$ for 30 seconds and primer extension at $72{ }^{\circ} \mathrm{C}$ for 1 minute. $1.5 \%$ agarose gel was casted and the amplified PCR product was mixed with $5 \mu \mathrm{l}$ of gel loading buffer. DNA ladder of $1 \mathrm{~kb}$ (HIMEDIA, Mumbai, Maharashtra, India) as a molecular marker was loaded along with samples. The gel was run and examined on UV transilluminator to visualize the bands. PCR products were purified by using the PCR Klenzol ${ }^{\mathrm{TM}}$ (Genei, Bangalore, India) and it was sequenced with an ABI Prism 3700 DNA Analyzer (Acme Progen Biotech (India) Pvt. Ltd., Salem, Tamilnadu, India). The nucleotide sequence $16 \mathrm{~S}$ rRNA gene region data of Bacillus cereus was submitted to NCBI database.

\section{Detection of Cholesterol oxidase production by qualitative and quantitative analysis}

\section{Qualitative analysis of Cholesterol oxidase}

Colony staining method

Colony staining method is to confirm the organism which producing Cholesterol oxidase. The filter disc were immersed into the solution containing $0.5 \%$ Cholesterol, 1.7\% 4-aminoantipyrin, 6\% Phenol and $3000 \mathrm{U} / \mathrm{L}$ Horseradish peroxidase (HRP) in $100 \mathrm{mM}$ Potassium buffer phosphate $(\mathrm{pH} 7.0)$. To the overnight grown bacterial colonies the immersed disc was placed on to the petriplate with Bacillus cereus strain KAVK4 and incubates at room temperature for $24 \mathrm{hrs}$. Development of red colour due to the formation of quinoneimine dye was confirmed the production of cholesterol oxidase (Lashkarian et al., 2010).

Cholesterol oxidase indicator plates

Bacillus cereus strain KAVK4 which producing Cholesterol oxidase were selected on Indicator plates containing $1.0 \mathrm{~g} / \mathrm{L}$ Cholesterol, $1.0 \mathrm{~g} / \mathrm{L}$ Triton X-100, 0.1g/L o-dianisidine and $1000 \mathrm{U} / \mathrm{L}$ horseradish peroxidase of LB agar medium. The overnight bacteria were cultured on these plates and incubate at $30^{\circ} \mathrm{C}$. The production of cholesterol oxidase which leads to the conversion of $\mathrm{H}_{2} \mathrm{O}_{2}$ from the bacterial cells and the reagent in the medium react with $\mathrm{H}_{2} \mathrm{O}_{2}$ to form azo compound which turns brown color (Lashkarian et al., 2010).

\section{Quantitative analysis of cholesterol oxidase}

Cholesterol oxidase activity was analyzed by measuring $\mathrm{H}_{2} \mathrm{O}_{2}$ generation (Allain et al., 1974). Briefly, the assay procedure is as follows to the $50 \mu \mathrm{l}$ crude enzyme were incubated with $3 \mathrm{ml}$ of solution A (4-amino-antipyrine, 1mmol/L; Phenol, 6mmol/L; Sodium azide, $0.2 \mathrm{~g} / \mathrm{L}$; Peroxidase, 5000U/L; Potassium phosphate buffer, $25 \mathrm{mmol} / \mathrm{L} \mathrm{PH}, 7.5$ )and $150 \mu \mathrm{l}$ of solution $\mathrm{B}($ Cholesterol, $8.26 \mathrm{mg} / \mathrm{ml}$; Triton X-100, 4.26\%; isoproponal for solvent) for 5 min at $37^{\circ} \mathrm{C}$, then boiled and was measured by spectrophotometry at $500 \mathrm{~nm}$. The enzyme activity was calculated as:

Enzyme activity $(\mathrm{U} / \mathrm{ml})=0.1315 \mathrm{~A}_{500} \times 3.2 \times 20 \div 5=1.6832 \times \mathrm{A}_{500}$

\section{Optimization of fermentation medium components for the production of cholesterol oxidase}

\section{Effect of different media for the production of cholesterol oxidase}

Production of Cholesterol oxidase was investigated by modifying the different media. The media such as Media 1(Ahmad and Johri 1992), Media 2(Modification of Arima, 1969), Media 3(Varma and Nene, 2003), Media 4 (Wu et al., 2015) and Media 5 (Ming-Tsung Lee et al., 1997) were taken. The amount of enzyme produced by Bacillus cereus strain KAVK4 at 12, 24, 32, 48, 64, 80 hrsof incubation time was determined by the enzymatic assay. The Media 1 showing maximum production of Cholesterol oxidase was selected for further optimization study. For the production of cholesterol oxidase, Medium 1 containing 0.1\% cholesterol, 2.0\% glucose, $0.5 \%$ yeast extract, $0.2 \% \mathrm{NH}_{4} \mathrm{NO}_{3}, 0.02 \% \mathrm{~K}_{2} \mathrm{HPO}_{4}$ and $0.03 \% \mathrm{MgSO}_{4} .7 \mathrm{H}_{2} \mathrm{O}$ (pH 7.0) (Ahmad and Johri, 1992) was used. Bacterial cells were grown at $30^{\circ} \mathrm{C}$ with shaking at $150 \mathrm{rev} \mathrm{min}^{-1}$.

\section{Effect of different carbon sources for the production of cholesterol oxidase}

Cholesterol oxidase production was investigated by modifying the medium with different carbon sources such as sucrose, fructose, maltose, glucose and xylose in the production medium at a concentration of $2.0 \%$. The amount of enzyme produced by the Bacillus cereus strain KAVK4 at 12, 24, 32, 48, $64,80 \mathrm{hrs}$ of incubation time was determined by the enzymatic assay. 


\section{Effect of different nitrogen sources for the production of cholesterol oxidase}

The influence of different nitrogen sources on cholesterol oxidase production was investigated by substituting yeast extract, ammonium nitrate of basal medium with different organic and inorganic nitrogen sources such as beef extract, peptone, ammonium chloride, sodium nitrate and ammonium nitrate at a concentration of $0.5 \%$ and $0.2 \%$. The amount of enzyme produced by the Bacillus cereus strain KAVK4at 12, 24, 32, 48, 64, $80 \mathrm{hrs}$ of incubation time was determined by the enzymatic assay.

\section{Effect of different metal ions for the production of cholesterol oxidase}

To investigate the effect of different metal ion on cholesterol oxidase production, cells were cultivated in the medium containing different metal ions such as zinc sulphate, managanese sulphate, ferrous sulphate, copper sulphate and magnesium sulphate at a concentration of $0.03 \%$. The amount of enzyme produced by the Bacillus cereus strain KAVK4 at 12, 24, $32,48,64,80 \mathrm{hrs}$ of incubation time was determined by the enzymatic assay.

\section{Effect of different $\mathrm{pH}$ for the production of cholesterol oxidase}

In order to investigate the effect of $\mathrm{pH}$ on cholesterol oxidase production, the selected bacterial isolate was cultivated with different $\mathrm{pH}$ such as $6,6.5,7.0,7.5,8.0$ in shake flask culture. The amount of enzyme produced by the Bacillus cereus strain KAVK4 at 12, 24, 32, 48, 64, 80 hrsof incubation time was determined by the enzymatic assay.

\section{Effect of different temperature for the production of cholesterol oxidase}

The influence of different temperature on cholesterol oxidase production was investigated using different temperature such as room temperature, $40^{\circ} \mathrm{C}, 50^{\circ} \mathrm{C}, 55^{\circ} \mathrm{C}, 65^{\circ} \mathrm{C}$. The amount of enzyme produced by the Bacillus cereus strain KAVK4 at 12, $24,32,48,64,80 \mathrm{hrs}$ of incubation time was determined by the enzymatic assay.

\section{Effect of different time for the production of cholesterol oxidase}

The optimized enriched media for the production of cholesterol oxidase was investigated using different time such as $12,24,32,48,64,80 \mathrm{hrs}$ of incubation time was determined by the enzymatic assay. Based on the effect of Carbon source, Nitrogen source, Metal ions source, $\mathrm{pH}$, Temperature and Time; the media was selected for the maximum production of cholesterol oxidase.

\section{RESULTS AND DISCUSSIONS}

Bacillus cereus strain KAVK4 was isolated from butter and identified based on the morphological and biochemical characteristics (Table 1). Bacillus cereus was gram positive, which shows positive result on catalase and sugar fermentation test. Hence 16S rRNA gene region was amplified and sequenced to identify and confirm the Bacillus cereus at molecular level and named the strain as KAVK4.

Table 1: Colony Morphology, Physical and Biochemical characterization of Bacillus cereus.

\begin{tabular}{lc}
\hline ColonyMorphology & Cream, Smooth and Flat colonies \\
\hline Physical Characterization & \\
\hline Gram stain & Gram Positive \\
\hline Biochemical characterization & \\
\hline Catalase test & + \\
Oxidase test & - \\
Indole production & - \\
Citrate Test & + \\
Sugar fermentation & + \\
\hline
\end{tabular}

+ POSITIVE, - NEGATIVE

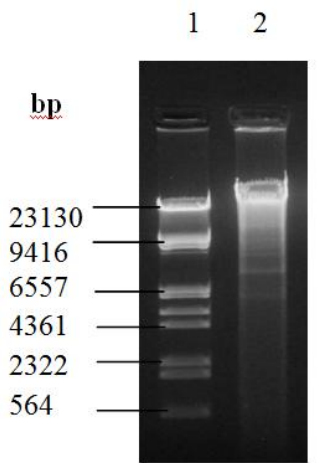

Fig 1: Genomic DNA of Bacillus cereus, 1- Lambda DNA / Hind III Digest Marker; 2- Genomic DNA of Bacillus cereus strain KAVK4.

Genomic DNA from Bacillus cereus strain KAVK4 was extracted (Figure 1). According to Jayachitra et al., 2012, 16S rRNA gene region of Bacillus cereus was amplified and sequenced. $1.5 \mathrm{~kb}$ size of discrete bands was observed in $1 \%$ agarose gel on UV illuminator. PCR amplification of 16S rRNA gene region using Forward and Reverse primers, the obtained PCR product resulted in $1366 \mathrm{bp}$ (Figure 2).

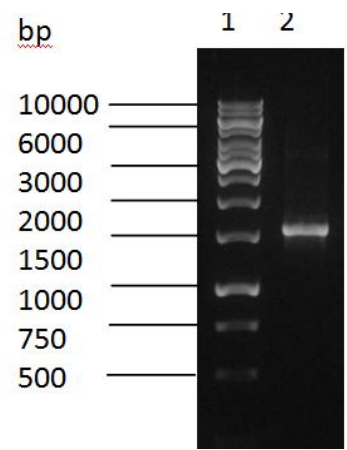

Fig. 2: PCR Product of Bacillus cereus, 1- 1Kb DNA Ladder; 2-PCR product of Bacillus cereus strain KAVK4.

The sequence data was submitted to NCBI and the accession number is KP792775. This was assessed for cholesterol lowering potential. According to Bholay et al., 2013, Cholesterol as sole source of carbon contained in the medium, the organism was inoculated in medium utilize the cholesterol and grown well. It must produce some enzymes which have ability to metabolite cholesterol. In my study nutrient agar medium with $1 \%$ 
concentration of cholesterol was prepared and the isolates were inoculated. It utilize cholesterol and grown well on the medium (Figure 3).

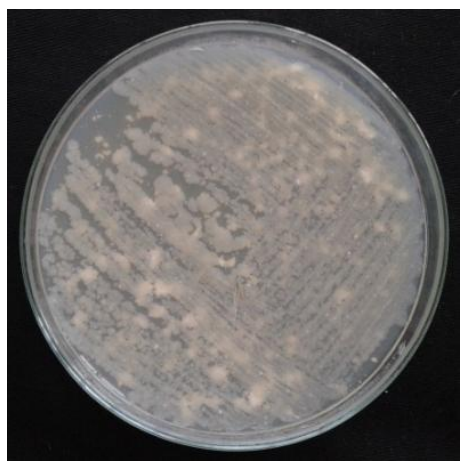

Fig. 3: Cholesterol degradation of Bacillus cereus strain KAVK4.

The production of cholesterol oxidase is assessed by qualitative and quantitative method. Colony staining method and Cholesterol oxidase indicator plate are used for qualitative method of analysis. This was confirmed with the development of red color (Figure 4).

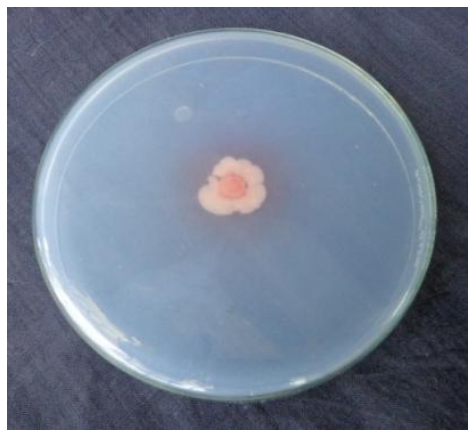

Fig. 4: Colony staining method of Bacillus cereus strain KAVK4.

In the indicator plate method, the medium color turns into brown because of the formation of azo component that was due to the presence of $\mathrm{H}_{2} \mathrm{O}_{2}$ generated by cholesterol oxidase (Figure 5) (Lashkarian et al., 2010).

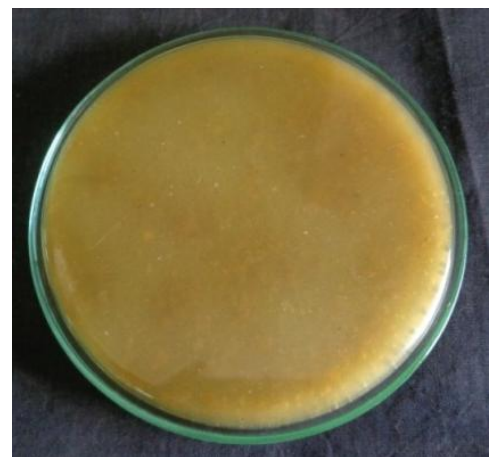

Fig. 5: Cholesterol oxidase indicator plate of Bacillus cereus strain KAVK4.

According to Kim et al., 2002, Bacillus subtilis from Korean traditional fermented flatfish, produced cholesterol oxidase in the medium containing $0.2 \%$ cholesterol. In fermented flatfish, the residual cholesterol was reduced by degrading potential of Bacillus subtilis due to the cholesterol oxidase production in the presence of oxygen (Kim et al., 2003). Based on this concordance, Bacillus cereus strain KAVK4 was confirmed for degradation of cholesterol. The optimization of Medium is required to improve cholesterol oxidase production. Based on these the carbon source, Organic and inorganic nitrogen source, metal ion source, $\mathrm{pH}$, temperature and time were modified for the maximum production of cholesterol oxidase. Some microorganisms have ability to grow and produce cholesterol oxidase in the presence of Tween 80 . Some microorganisms were effectively produced cholesterol oxidase based on the temperature. The optimum temperature for this enzyme production Rhodoccococus equi was at $47^{\circ} \mathrm{C}$ and Corynebacterium cholesterolicum production of this enzyme was at $40^{\circ} \mathrm{C}$ respectively (Salva et al., 1999). Streptomyces fradiae and Brevibacterium $s p$. showed optimum stability for $30 \mathrm{~min}$ at $50^{\circ} \mathrm{C}$ and $53^{\circ} \mathrm{C}$ respectively (Yazdi et al., 2001b; Fujishiro et al., 2002). The optimum $\mathrm{pH}$ for the enzyme activity was between 7.0 and 8.0 was observed in Actinomyces lavendulae mycelium, Corynebacterium cholesterolicum, Streptoverticillium cholesterolicum, Rhodococcus equi and Streptomyces violascens (Lashkarian et al., 2010). Among the five different media, media 1 showed maximum production was about $0.75 \mathrm{U} / \mathrm{ml}$ and was selected for further modification to enhance the production of cholesterol oxidase (Figure 6).

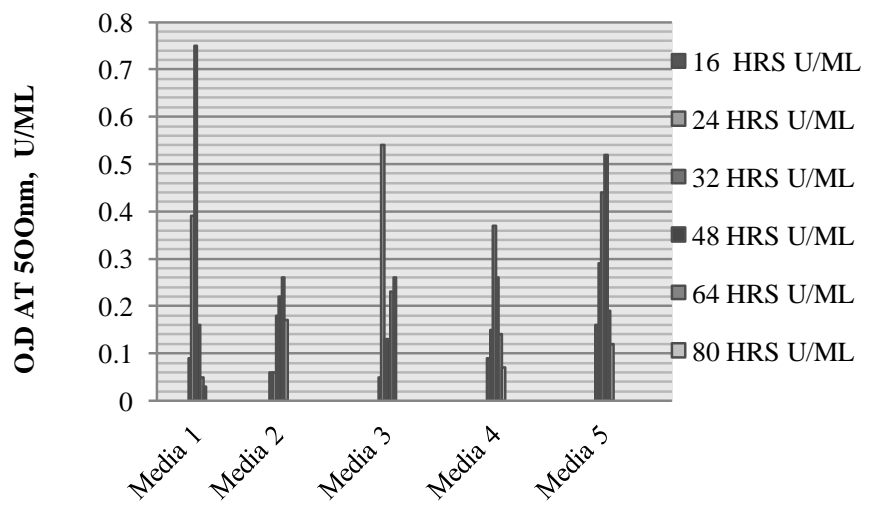

DIFFERENT MEDIA

Fig. 6: Effect of different media for the production of cholesterol oxidase.

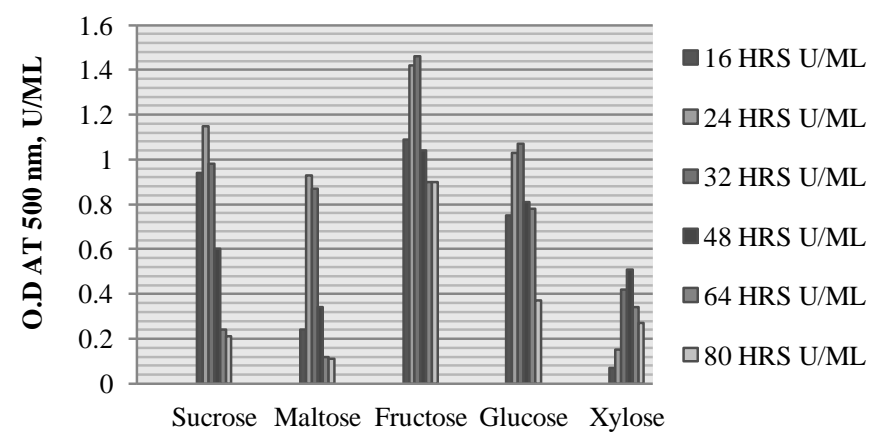

DIFFERENT CARBON SOURCE

Fig. 7: Effect of different carbon source for the production of cholesterol oxidase. 
Fructose enriched media showed highest production was about $1.46 \mathrm{U} / \mathrm{ml}$ (Figure 7). In the organic and inorganic nitrogen source of media, Beef extract and Ammonium nitrate enriched media were produced cholesterol oxidase was about 1.05 and 1.42 $\mathrm{U} / \mathrm{ml}$ respectively (Figure 8 ).

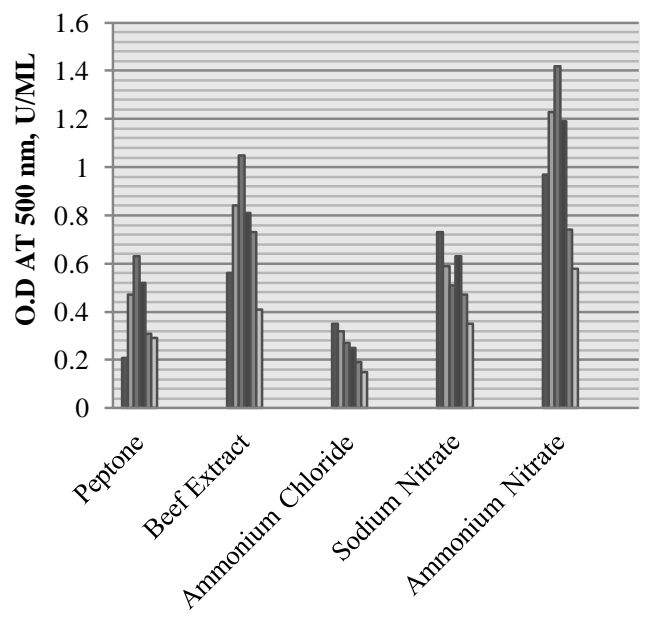

- 16 HRS U/ML $\square 24$ HRS U/ML $\square 32$ HRS U/ML - 48 HRS U/ML $\square 64$ HRS U/ML $\square 80$ HRS U/ML

\section{DIFFERENT NITROGEN SOURCE}

Fig. 8: Effect of different nitrogen source for the production of cholesterol oxidase.

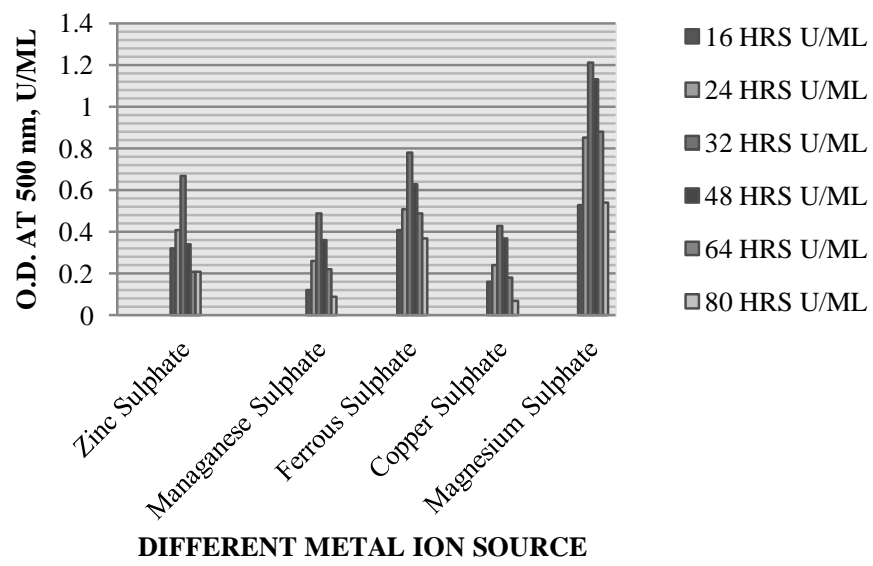

Fig. 9: Effect of different metal ion source for the production of cholesterol oxidase.

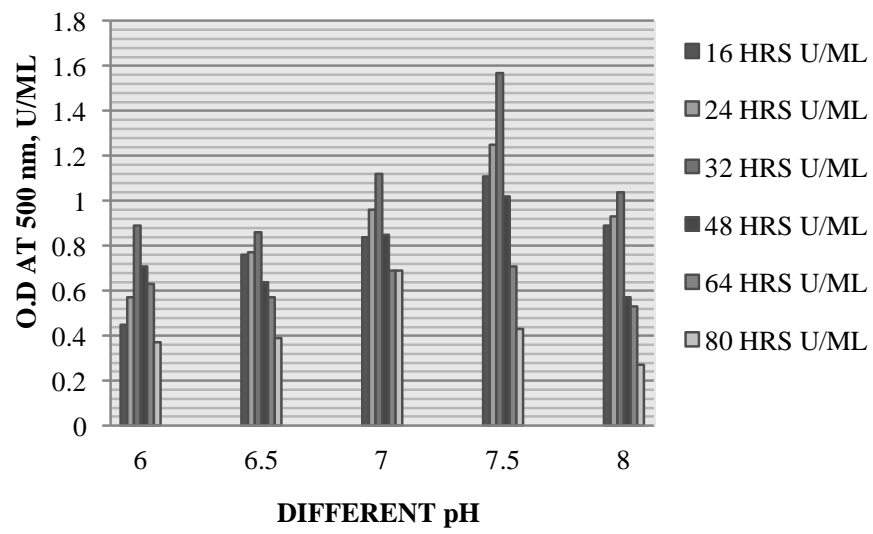

Fig. 10: Effect of different $\mathrm{pH}$ for the production of cholesterol oxidase.
For the metal ion source, magnesium sulphate showed maximum of about $1.21 \mathrm{U} / \mathrm{ml}$ respectively (Figure 9). The optimum $\mathrm{pH}$ for the production of cholesterol oxidase was at $\mathrm{pH} 7.5$ of $1.57 \mathrm{U} / \mathrm{ml}$ (Figure 10) and the temperature required for the optimum production of cholesterol oxidase at Room temperature was about $0.97 \mathrm{U} / \mathrm{ml}$ (Figure 11).

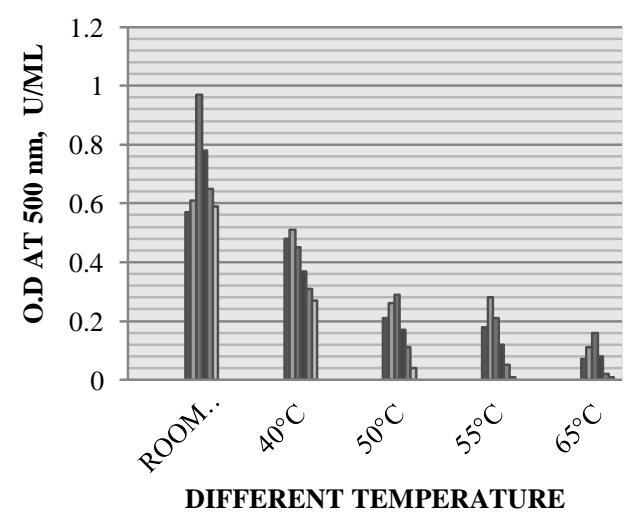

- 16 HRS U/ML $\square 24$ HRS U/ML $\square 32$ HRS U/ML

- 48 HRS U/ML

口 64 HRS U/ML

$\square 80 \mathrm{HRS}$ U/ML

Fig. 11: Effect of different temperature for the production of cholesterol oxidase

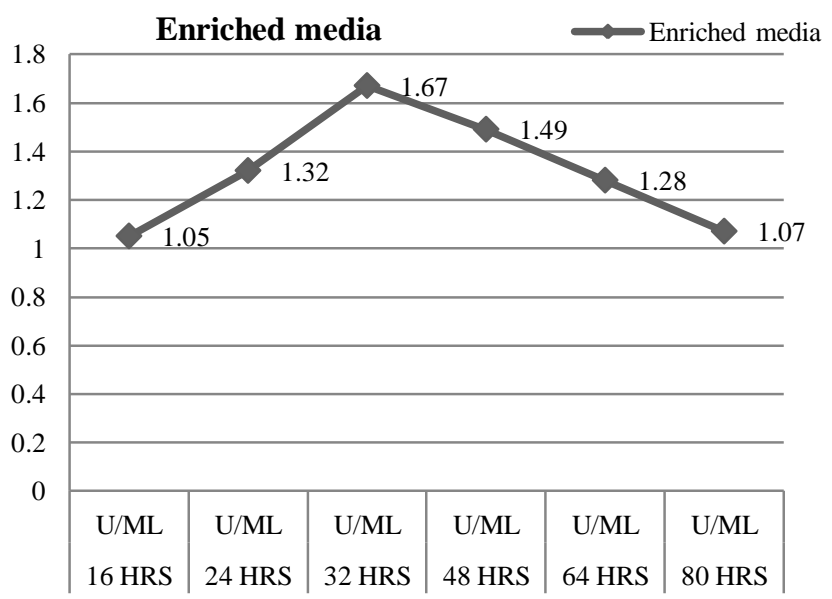

Fig. 12: Effect of different time for the production of cholesterol oxidase.

The enriched medium which showed maximum production was selected for further study. Hence the Bacillus cereus strain KAVK4 showed maximum production of $1.67 \mathrm{U} / \mathrm{ml}$ at 32 hours of incubation period (Figure 12).

\section{CONCLUSION}

Application of cholesterol oxidase is commercial and medical important. For this reason, the Bacillus cereus strain KAVK4 which are capable of producing maximum levels of cholesterol oxidase have been isolated and identified. For better identification, $16 \mathrm{~S}$ rRNA gene region was amplified and sequenced to confirm the species at molecular level. The optimization ofcholesterol oxidase production by Bacillus cereus strain KAVK4 should prove that increase the oxidation of 
cholesterol and converts into 4-cholesten-3-one and other derivatives with the reduction of $\mathrm{O}_{2}$ to $\mathrm{H}_{2} \mathrm{O}$ faster.

\section{REFERENCES}

Ahmad S, Johri BN. Sterol bioconversion using Rhodococcus equi in organic-aqueous two-lipid phase system. Indian J Microbiol, 1992; 32: 489-491.

Allain CC, Poon LS, Chan CS, Richmond W, Fu PC. Enzymatic determination of total serum cholesterol. Clin Chem, 1974; 20(4):470 475 .

Arima K, Nagasawa M, Bae M, Tamura G. Microbial transformation of steroids. Part I. Decomposition of cholesterol by microorganisms. Agric Biol Chem. 1969; 33:1636-1643.

Bholay AD, Gadekar DJ, Sawant SK, SonawaneSM. Bacterial extracellular cholesterol oxidase and its pharmaceutical perspectives. Int J Curr Microbiol App Sci, 2013; 2(3): 19-28

Constantinides A. Steroid transformation at high substrate concentrations using immobilized Corynebacterium simplex cells. Biotechnol Bioeng, 1980; 22(1): 119-136.

Fujishiro K, Uchida H, Shimokava K, Nakano M, Sano F, Ohta T, Nakahara N, Aisaka K, Uwajima T. Purification and properties of a new Brevibacterium sterolicum cholesterol oxidase produced by E.coli MM294/pnH10. J FEMS Microbiol Lett, 2002; 215 (2): 243-248.

Jayachitra A, Krithiga N, Bavani C. Isolation, molecular characterisation and sequencing of cholesterol degrading bacteria. Int $\mathbf{J}$ Pharm Life Sci, 2012; 3(9): 1946-1952

Kaunitz H. Degradation of cholesterol oxidase by Bacillus subtilis SFF34 in flatfish during fermentation. Lipids, 1978; 13: 373-375.

Kim KP, Rhee CH, Park HD. Degradation of cholesterol by Bacillus subtilis SFF 34 isolated from Korean traditional fermented flatfish. Lett Appl Microbiol, 2002; 35: 468-472.

Kim KP, Rhee IK, Park HD. Degradation of Cholesterol by Bacillus Subtilis SFF 34 in flatfish during fermentation. J Microbiol, 2003;41(4): 284-288.

Lashkarian H, Raheb J, Shahzamani K, Shahbani H, Shamsara M. Extracellular cholesterol oxidase from Rhodococcus sp: Isolation and molecular characterization. Iran Biomed J, 2010; 14 (1-2): 49-57.

Lata Kumari, Shamsher S. Kanwar. Cholesterol oxidase and its applications. Adv Microbiol, 2012; 2: 49-65

Ming-Tsung Lee, Wen-Chang Chen, Cheng-Chun Chou. Medium improvement by orthogonal array designs for cholesterol oxidase production by Rhodococcus equi No. 23. Process Biochem, 1997; 32(8): 697-703
Pitcher DG, Saunders NA, Owen RJ. Rapid extraction of bacterial genome DNA with guanidium thiocyanate. Lett Appl Microbiol, 2008; 8(4):151-156

Sakodinskaya IK, Alexander D. Ryabov. Crown ether activates cholesterol oxidase in low water media. Biotechnol Lett, 2000; 22: 173 176.

Salva TJG,Liserre AM, Moretto AL, Zullo MAT, Ventrucci G, Menezes TJB. Some enzymatic properties of cholesterol oxidase produced by Brevibacterium sp. Revista de Microbiologia, 1999; 30 (4): 315-323.

Smith AG, Brooks CJW. Cholesterol oxidase: properties and application. J Steroid Biochem, 1976; 7: 705-713.

Varma R, Nene S. Biosynthesis of cholesterol oxidase by Streptomyces lavendulae NCIM 2421. Enzyme microb Technol,2003; 33: 286-291.

Watanabe K, Shimizu H, Aihara H, Nakamura R, Suzuki KI, Momagata K. Isolation and identification of cholesterol degradation Rhodococcus strains food of animal origin and their cholesterol oxidase activities. J Gen Appl Microbiol, 1986; 32: 137-147.

Williams and Wilkins., $9^{\text {th }}$ Edition. Bergey's Manual of determinative bacteriology, 1994

Wu K, Li W, Song J, Li T. Production, purification, and identification of Cholest-4-en-3-one produced by Cholesterol oxidase from Rhodococcus sp. in aqueous/organic biphasic system. Biochem Insights, 2015; 8(S1): 1-8 doi:10.4137/BCI.S21580.

Yazdi MT, Yazdi ZT, Ghasemian A, Zarrini G, Olyaee NH, Sepehrizadeh Z. Purification and characterization of extra-cellular cholesterol oxidase from Rhodococcussp. PTC1633. Biotechnology, 2008; 7(4):751-756.

Yazdi MT, MalekzadehF, Zarrini GH, Faramarzi MA, KamranpourN, Khaleghparast SH. Production of cholesterol oxidase by a newly isolated Rhodococcus sp. World J Microbiol Biotechnol,2001a; 17 731-737.

YazdiMT, Zahraei M, Aghaepour K, Kamranpour N. Purification and partial characterization of cholesterol oxidase from Streptomyces fradiae, Enzyme Microb Tech, 2001b; 18 (4-5):410-414.

\section{How to cite this article:}

Amutha K, Kokila V. Optimization of cholesterol oxidase production and $16 \mathrm{~S}$ rRNA partial sequence of Bacillus cereus strain KAVK4 isolated from butter. J App Pharm Sci, 2016; 6 (07): 061066. 